Espacio y Desarrollo $\mathrm{N}^{\circ} 35,2020$, pp. 71-98 (e-ISSN 2311-5734)

https://doi.org/10.18800/espacioydesarrollo.202001.003

\title{
Infraestructura ciclovial en Lima, Perú: estudio de caso DISTRITO DE MirAFLORES
}

Natalia Aste Cannock

https://orcid.org/0000-0001-5325-4512

Geografía y Medio Ambiente, Facultad de Letras y Ciencias Humanas,

Pontificia Universidad Católica del Perú, Lima, Perú

naste@pucp.pe

Daniel Concepción Solis

https://orcid.org/0000-0001-6780-1986

Geografía y Medio Ambiente, Facultad de Letras y Ciencias Humanas,

Pontificia Universidad Católica del Perú, Lima, Perú

daniel.concepcion@pucp.pe

Carolina García Pye

https://orcid.org/0000-0001-9066-0499

Geografía y Medio Ambiente, Facultad de Letras y Ciencias Humanas,

Pontificia Universidad Católica del Perú, Lima, Perú carolina.garcia@pucp.pe

Walther Daniel Montes Álvarez

https://orcid.org/0000-0002-2862-0119

Geografía y Medio Ambiente, Facultad de Letras y Ciencias Humanas,

Pontificia Universidad Católica del Perú, Lima, Perú daniel.montes@pucp.pe

Alberto E. García-Rivero

https://orcid.org/0000-0002-8344-9529 Autor de correspondencia: Escuela Profesional de Geografía,

Facultad de Ciencias Sociales, Universidad Nacional Mayor de San Marcos, Lima, Perú albertoenrique.garcia@unmsm.edu.pe 


\section{RESUMEN}

La ciudad de Lima presenta un desarrollo muy desigual de ciclovías en todos sus distritos, donde se destaca el distrito de Miraflores como el de mayor desarrollo. El presente trabajo tuvo como objetivo evaluar la infraestructura para bicicletas en este distrito. La metodología aplicada combinó el levantamiento terrestre, con levantamientos virtuales y procesamiento de imágenes satelitales en un entorno GIS. Esta evaluación se realizó sobre la base de los principales aspectos relacionados con ciclo-inclusividad, seguridad, coherencia, dirección e infraestructura del ciclo. Entre los principales resultados, destacan que los niveles de seguridad son bajos, lo que permite inferir que se debe promover un mayor número de carriles bici físicamente segregados. La coherencia es muy pobre en lograr conectar varios puntos de origen y destino, con numerosos cruces. Aunque las rutas principales son bastante directas, la mala ubicación de los aparcamientos para bicicletas y la distribución desigual de la red la hacen todavía muy ineficiente. A pesar de las deficiencias que aún presenta esta infraestructura ciclista en Miraflores, se evidencia una fuerte diferenciación con el resto de la ciudad de Lima, debido, entre otras causas, a una alta informalidad en el sector del transporte, derivada de la aplicación de políticas neoliberales que han profundizado las amplias desigualdades territoriales y sociales en esta ciudad. La pandemia COVID-19 ha incorporado un nuevo tipo de ciclistas, vinculados a los sistemas de «entrega», que evidencia aún más las limitaciones de la infraestructura de bicicletas en toda la ciudad.

Palabras clave: Direccionalidad, SEguridad, COHERENCiA, CiClo-INClusividad, Miraflores.

\section{Bicycle path infrastructure in lima, Peru: Miraflores district case study}

\section{Abstract}

The city of Lima presents a very uneven development of bicycle lanes in all its districts, where the district of Miraflores stands out as the one with the greatest development. The present work aimed to evaluate the bicycle infrastructure in this district. The applied methodology combined the land survey, with virtual surveys and processing of satellite images in a GIS environment. This evaluation was made based on the main aspects related to cycle-inclusivity, security, coherence, direction, and infrastructure of the cycle. Among the main results, they stand out that the safety levels are low, which allows to infer that a greater number of physically segregated bike lanes should be promoted. The coherence is very poor in managing to connect several points of origin and destination, with numerous crossings. Although the main routes are fairly direct, the poor location of the bicycle parking facilities and the uneven distribution of the network still make it very inefficient. Despite the deficiencies that this cycling infrastructure still presents in Miraflores, there is a strong differentiation with the rest of the city of Lima, due, among other causes, to a high informality in the transport sector, derived from the application of policies neoliberals who have deepened the wide territorial and social inequalities in this city. The COVID-19 pandemic has brought in a new breed of cyclists, linked to «delivery» systems, further evidence of the limitations of the bicycle infrastructure throughout the city.

Keywords: Directionality, security, coherence, cycle-inclusivity, Miraflores. 


\section{INTRODUCCIón}

Los movimientos de personas, mercancías e información han acompañado el desarrollo de las diferentes sociedades en el devenir histórico y se han caracterizado por un aumento creciente de la movilidad y de mayores niveles de accesibilidad, fundamentalmente desde la segunda mitad del siglo XX, con la liberalización del comercio y las considerables mejoras tecnológicas. Esto ha provocado que las sociedades sean cada vez más dependientes de sus sistemas de transporte (Rodrigue, Comtosis \& Slack., 2017).

Esas dependencias han motivado, principalmente en las grandes ciudades y metrópolis, altos niveles de congestión vehicular y de porción de la superficie de la ciudad, dedicada a la infraestructura vial, con la consiguiente pérdida de áreas verdes y de recreación, aumento de la contaminación ambiental y del tiempo que las personas deben dedicar para desplazarse a sus lugares de estudio, trabajo y principales proveedores de servicios. No obstante, cada territorio con sus características propias debe gestionar la problemática del transporte y debe tener en cuenta, la infraestructura vial existente, el parque automotor circulante, los sistemas públicos y colectivos de trasportación de pasajeros, la cultura vial de la población, los cuerpos normativos y legislativos sobre la materia vial, entre otras muchas más variables, que intervienen en la configuración de la dinámica urbana del transporte.

Según la CEPAL (2017), «América Latina ha experimentado un proceso de urbanización tan rápido que ha sido calificado de explosión urbana y como resultado es hoy la región en desarrollo más urbanizada del mundo. Su población total ha sido estimada en 623 millones de personas, de las cuales un porcentaje de 79,5\% habita en zonas urbanas». Ante este escenario, la capacidad de movilidad de las personas, fundamentalmente las de menores ingresos, está más limitada, debido a la creciente cantidad de habitantes que se desplazan en transporte privado, reduciendo significativamente el espacio para el crecimiento del transporte público.

Por lo tanto, se hace necesario revertir esta tendencia, a partir de la reducción del transporte motorizado privado, a fin de desarrollar sistemas de transporte atractivos, accesibles y asequibles, que estén al alcance de todos los habitantes de la ciudad. Sistemas multimodales de transporte, que se integren a las estrategias de movilidad urbana, los cuales estimulen el uso del transporte no motorizado, tal como la circulación peatonal o el ciclismo, debiendo adaptar las vías para la inclusión de veredas, pasos de peatones y ciclovías (ONU-Habitat, 2016).

En los países latinoamericanos, la solución más común, bajo el manto de las políticas neoliberales, ha infravalorado la utilidad e importancia de desarrollar modernos, articulados y cada vez menos contaminantes sistemas de transporte masivos y públicos, potenciando un crecimiento sostenido de la infraestructura vial para automóviles, 
tanto al interior, como en la periferia de las ciudades. Esta medida, lejos de solucionar el problema, conlleva a un mayor crecimiento horizontal de la ciudad en las periferias, con un aumento en la distancia a recorrer y el número de automóviles, un típico ciclo vicioso, que incrementa el flujo, los niveles de congestión vehicular y todos los impactos derivados de los mismos.

Sin embargo, esta problemática ha sido abordada de forma muy diferente por países europeos como Francia, Dinamarca o los Países Bajos, por solo citar algunos, a través de la implementación de sistemas de transporte intermodal y la promoción del uso de sistemas de transporte alternativos como las bicicletas, debido a sus capacidades para reducir la congestión vehicular y las emisiones de $\mathrm{CO} 2$, además de generar significativas mejoras en la calidad de vida en sus ciudades (Velde, Eerdmans \& Westerink, 2010). De este modo, el ciclismo urbano se presenta como una opción de movilidad con alto potencial para reducir problemas urbanos y avanzar hacia el desarrollo de ciudades sostenibles competitivas (Ríos, Taddia, Pardo \& Lleras, 2015).

En un informe del BID (2015) se expone la necesidad de que, en los países latinoamericanos y caribeños, se promueva el uso de la bicicleta, apelando a la formulación de políticas de movilidad, que incluyan a la bicicleta; así como que se pueda implementar una infraestructura orientada a su uso para que tenga un impacto positivo en la movilidad de los ciudadanos. En el propio informe, se hace un levantamiento de la infraestructura ciclovial y el número de viajes que se producen en las principales ciudades de esta área geográfica, la cual, si bien representa un incremento respecto a décadas anteriores, aún está muy distante de las potenciales de este transporte individual alternativo (Figura 1).

Orellana, Hermida y Osorio (2017) afirman lo siguiente:

Nos encontramos en un momento de transición en lo que respecta a la planificación de las ciudades, momento en el cual se incorporan nuevas variables relacionadas con la sustentabilidad ambiental y social. En este contexto de cambio, se empieza a ver a la movilidad no motorizada como una alternativa casi obligatoria para mitigar los impactos negativos producidos por años de planificación en función del vehículo privado. Pero como todo proceso de cambio, aún no se cuenta con las herramientas ni soluciones definitivas de implementación (pp. 176-177).

En la encuesta del Observatorio Lima Cómo Vamos (2017), cuyos resultados relacionados con los aspectos que más afectan la calidad de vida de la población de la ciudad de Lima, se reporta que la delincuencia e inseguridad ciudadana ha sido considerada como el principal problema, seguido por el transporte público y la contaminación ambiental. Estos resultados se repiten desde 2010 para el caso de la capital peruana. 
Figura 1. Kilómetros de infraestructura vial para bicicleta (a) y número de viajes en bicicletas por día (b), en las principales ciudades de América Latina

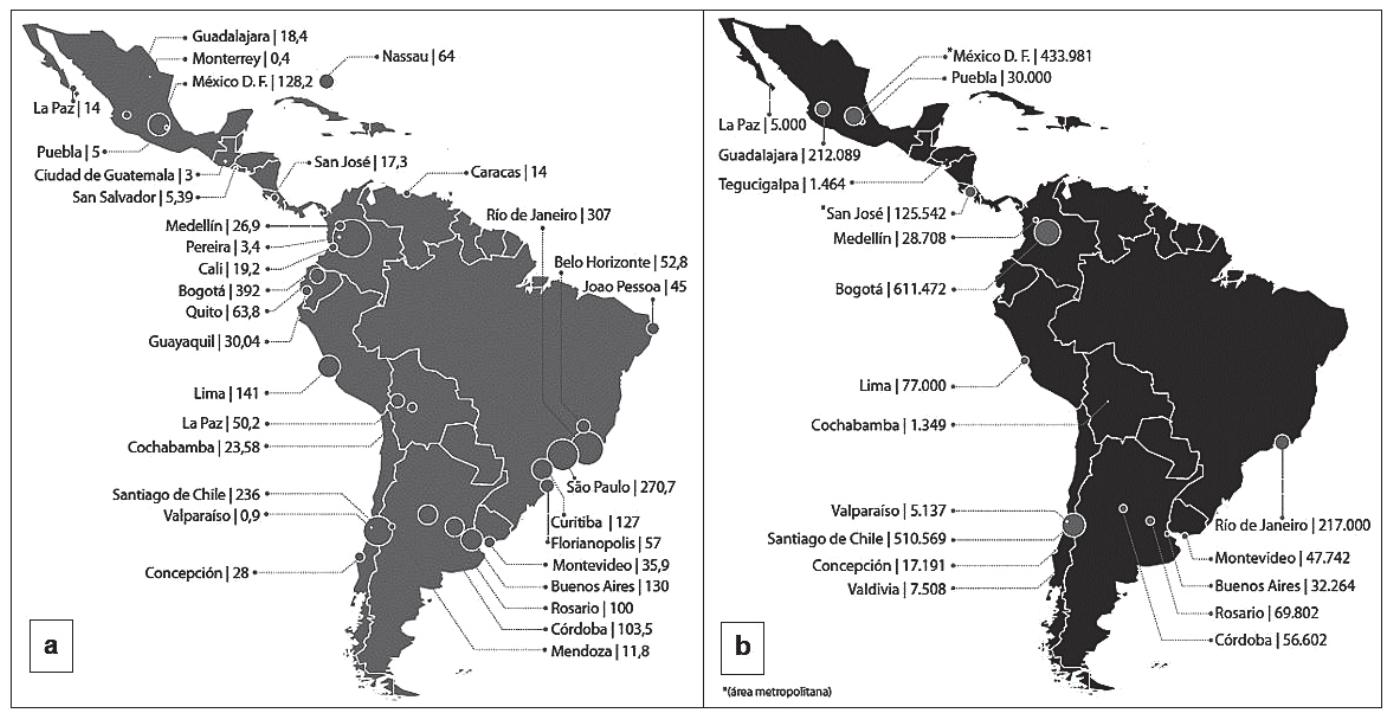

Fuente: Ríos et al., 2015.

La propia encuesta, realizada en la ciudad de Lima, demuestra que la insatisfacción con los espacios para peatones es altísima $(45,9 \%)$, así como la insatisfacción en lo referente a las ciclovías (53,4\%). El 31,9\% manifiesta que el aumento de veredas y espacios públicos será la medida que más lo beneficiaría. Así mismo, un $6 \%$ cree que se beneficiará más con la implementación de un sistema de préstamo de bicicletas. En esta ciudad, se han realizado acciones de promoción de uso de bicicletas e implementación de proyectos de construcción y rehabilitación de infraestructura ciclovial y de estacionamientos (Ríos et al., 2015). A pesar de ello, el modelo intermodal y los transportes alternativos no han alcanzado niveles significativos de desarrollo como en otras ciudades latinoamericanas. Esto se debe a la carencia de una red ciclovial interconectada y a una infraestructura deficiente.

Además, la configuración espacial de la red ciclovial (aproximadamente, $141 \mathrm{~km}$ ) presenta una clara disparidad espacial en cuanto a su cobertura, al igual que una baja conectividad. En Lima Centro se concentra la infraestructura ciclovial, mientras que Lima Norte y Sur se encuentran totalmente desatendida; dando como resultado solo un $0,3 \%$ de viajes realizados en bicicleta (Ríos et al., 2015) (Figura 2). 
Figura 2. Red de ciclovías de Lima Metropolitana

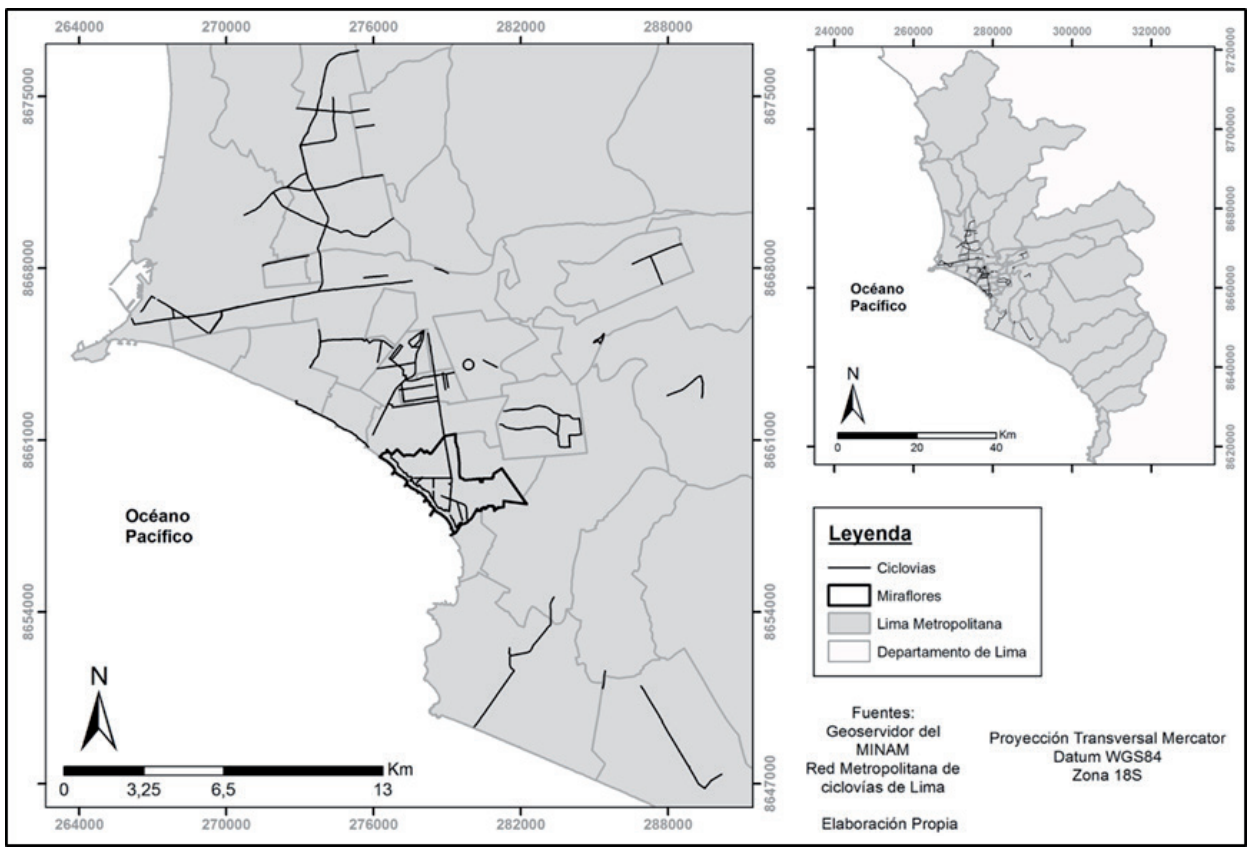

F...

\section{Antecedentes}

La seguridad de la infraestructura ciclovial ha sido ampliamente analizada en investigaciones internacionales (Gurine, 2016; Landis, Vattikuti, \& Brannick, 1997; Rybarczyk $\&$ Wu, 2010). Para cuantificar la seguridad se ha recurrido a índices para modelar la comodidad de los ciclistas (Rybarczyk \& Wu, 2010). Uno de los índices más populares es el «Bicycle Level of Service» (BLOS) desarrollado por Landis et al. (1997), el cual se basa en la percepción de los usuarios. El BLOS requiere una serie de parámetros entre ellos volumen de tráfico por carril, velocidad de los vehículos, potencial de generación de tráfico en intersecciones, condición y ancho de las vías. No obstante, ello se presenta como una limitación para zonas de estudio donde no hay una recogida sistemática de estos datos. La percepción de seguridad también ha sido evaluada en relación con la observación de la infraestructura (Winters et al., 2012; Gurine, 2016). El principal instrumento para evaluar la percepción de los usuarios son las encuestas. Estudios como el de Sanders (2008) han aplicado únicamente encuestas para evaluar la percepción de seguridad, considerando variables adicionales como alumbrado y calidad de la infraestructura. 
Para el análisis de la coherencia varios autores recurren a la combinación de métodos cualitativos y cuantitativos, a fin de identificar elementos variados que permitan identificar la conexión de los componentes de las ciclovías. Así, consideran las características de los ciclistas, sus comportamientos de viaje, el volumen de ciclistas en las vías, entre otras variables. En ese sentido, Pettinga et al. (2009) proponen un mapeo participativo como procedimiento para identificar una red de uso de bicicletas. Consideran desarrollar una cartografía de los usos de suelo, origen y destino de los viajes, las rutas de viaje, las instalaciones existentes, los accidentes relacionados al ciclismo y los volúmenes de ciclistas. Por otra parte, Suzuki et al, (2012) proponen el método OLIVE que permite averiguar las características de los viajes en bicicleta de manera cuantitativa y cualitativa, extrae puntos problemáticos considerando el comportamiento de viaje de los usuarios, utilizando el registro de ruta de viaje de los encuestados y el número observado de bicicletas.

Otros autores como Panter et al., 2019, a partir de una extensa revisión bibliográfica, concluyeron que, de todos los cambios físicos del entorno, los que más impulsan a las personas a desarrollar caminata y el ciclismo, son aquellos que mejoran la accesibilidad y la conectividad; así como aquellos que producen un mejoramiento en la seguridad vial y personal.

Sin embargo, Beura, et al., 2020, en un estudio realizado en ciudades medias de la India, concluyeron en su estudio que un entorno insalubre desalienta en gran medida el uso de bicicletas como modo de elección de transporte (ya que los usuarios tienen más probabilidades de estar expuestos a peligros ambientales). De igual forma, afirman que la calidad del aire es muy importante para los ciclistas, así como las características de las vías tales como el volumen de tráfico, su ancho y el desarrollo de las actividades comerciales en las mismas.

Para el caso de Lima Metropolitana, el desarrollo de investigaciones sobre bicicletas como modo de transporte, aún es limitado; aunque en 2017 se creó el «Manual de Criterios de Diseño de Infraestructura Ciclo-Inclusiva y Guía de Circulación del Ciclista», el cual tiene como objetivo fundamental definir lineamientos y criterios de diseño ciclo-inclusivo para fortalecer los conceptos técnicos de los planificadores, diseñadores urbanos y estudiantes de temas urbanos y viales, contando además con una Guía de circulación del ciclista, que brinda una serie de reglas y recomendaciones de circulación para orientar a los usuarios de la bicicleta y demás actores de la vía. (Municipalidad de Lima, 2017). Este documento sienta las bases para el diseño de infraestructura ciclo-inclusiva y la incorporación de las bicicletas a las dinámicas urbanas. Para ello, nuevamente, toman los cinco requerimientos mencionados con anterioridad, junto con una serie de consideraciones de diseńo de la infraestructura. Entre los pasos considerados para lograr una red ciclovial densa y conectada se considera el desarrollo de un mapa de viajes (origen y destino), cartografía de la infraestructura existente y de necesidades de su mejoramiento 
Además, se enfatiza la intermodalidad del transporte público, en la cual la bicicleta constituye una especie de sistema alimentador, que permite acercar a las personas a los diferentes medios masivos de transporte público de una forma ágil, directa y barata. (Municipalidad de Lima, 2017). Sin embargo, el documento asume que ya existe un sistema de transporte público masivo cuando en realidad solo hay una línea de metro (tren urbano eléctrico), dos rutas de buses gestionadas por la Municipalidad y un número reducido de líneas viales preferenciales para el sistema de buses Metropolitano. El resto es un sistema informal de microbuses y buses que muchas veces no respetan los paraderos, ni los tiempos de llegada a estos, y compiten agresivamente por pasajeros. Asimismo, la investigación propone una mejora del sistema de transporte alternativo e intermodal en Lima Metropolitana. Además, se propone la creación de estacionamientos públicos de bicicletas, implementación de señalización y ciclovías segregadas.

La revisión de la bibliografía internacional y nacional sobre el transporte por bicicleta expone la necesidad de incidir en la infraestructura ciclovial a fin de asegurar su uso efectivo, en el cual los ciclistas opten por la bicicleta como modo de transporte prioritario. En ese marco, para impulsar el uso de bicicletas es esencial asegurar una infraestructura ciclovial eficiente, inclusiva y de alta calidad

Las ciclovías deben ser seguras, coherentes, directas, cómodas y atractivas. De eso requerimientos, los tres primeros son fundamentales (Pettinga, 2009; Sanders, 2008). Las rutas coherentes deben satisfacer las necesidades de diferentes usuarios, esta red debe ser capaz de soportar desplazamientos desde distintos orígenes y destinos y demás, ofrecer continuidad de rutas mediante una relación lógica de vías sin interrupciones, ni cambios de diseño incomprensibles para los usuarios. La seguridad es un factor determinante en el uso de bicicletas como modo de transporte y en la elección de rutas (Rybarczyk \& Wu, 2010; Winters et al., 2012; Saplioglu \& Yüzer, 2016), en la que tanto usuarios reales como potenciales identifican a la inseguridad real o percibida como un factor que disuade la circulación en bicicletas (Winters et al., 2012; Larsen, Patterson \& El-geneidy 2013). El diseño de rutas directas implica que estas sean lo más directas y lógicas posibles, evitando obstáculos innecesarios y demoras en el viaje. Las demoras en las ciclovías se generan por intersecciones en las que el ciclista no tiene preferencia, mientras que los obstáculos implican el tomar rutas indirectas, que recorren más distancia de la necesaria (Pardo \& Sanz, 2016).

\section{3. ÁREA DE ESTUdio}

Lima Metropolitana cuenta con, aproximadamente, nueve millones de habitantes, que se distribuyen en 43 distritos. Miraflores, es uno de los principales distritos de Lima, ya que está ubicado estratégicamente, lo que ha hecho que el distrito funcione como un importante centro comercial, financiero y turístico (Figura 3). 
Figura 3. Ubicación del distrito de Miraflores, Lima

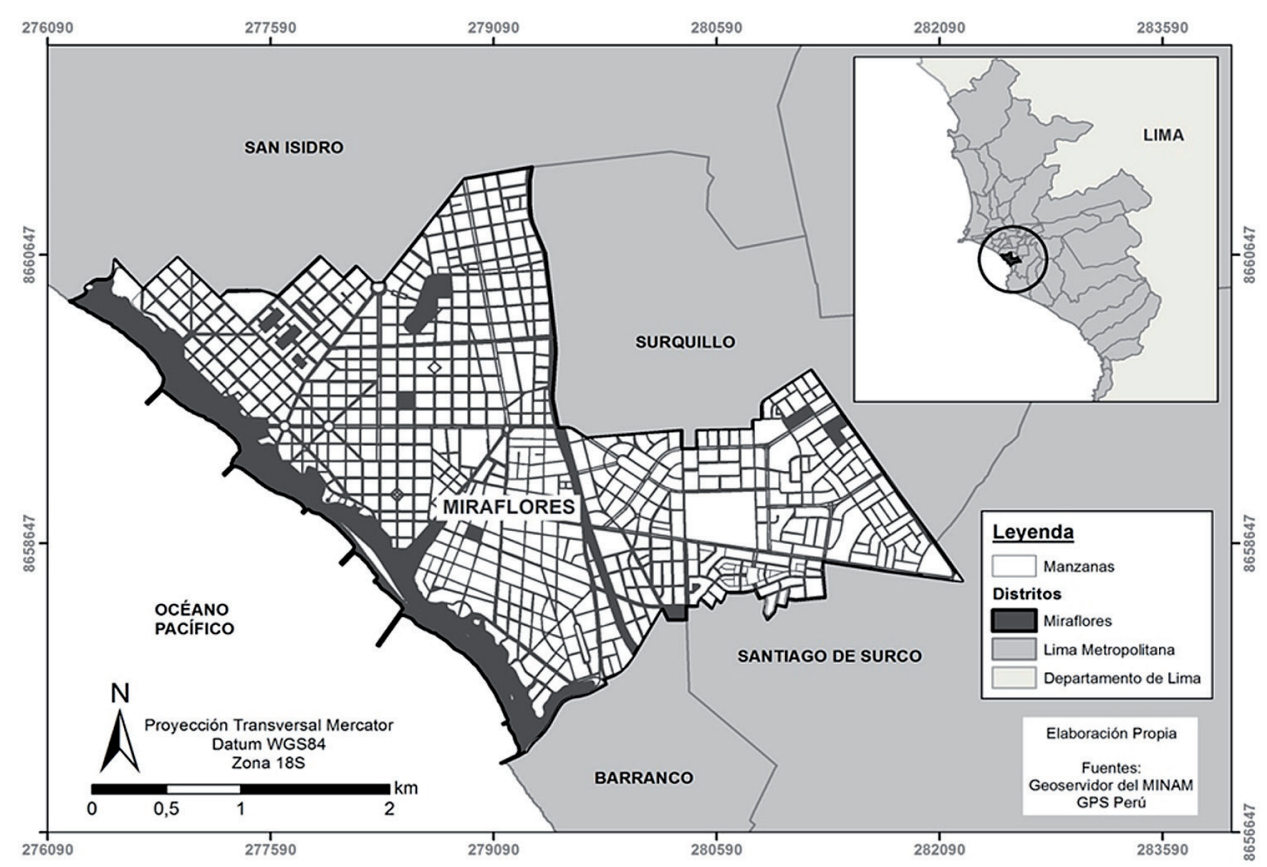

Ello a su vez hace que sea el distrito con el más alto índice de desarrollo humano, menores indicadores de pobreza, lo que se refleja en el alto nivel de calidad de vida gracias a un adecuado equipamiento urbano y calidad de servicios básicos (Municipalidad de Miraflores, 2017). El distrito abarca $9,62 \mathrm{~km}^{2}$ y en la actualidad, cuenta con una población estimada de unos 99337000 habitantes, lo que representa el $0.3 \%$ de la población total del país (INEI, 2017).

En Miraflores, existe una demanda diaria de transporte y movilidad de cerca de 150000 personas, de las cuales la mitad no vive en el distrito, y la mayoría de los viajes se realiza en transporte público. Para responder a esta gran demanda, existe un total de 94 rutas de transporte público que transitan por el distrito, lo cual supone un número muy alto en comparación con las necesidades reales (Municipalidad de Miraflores, 2016). Además, existe un excesivo uso de vehículos particulares, por lo que se busca desincentivar el uso del auto y promover el uso de la bicicleta (Municipalidad de Miraflores, 2017).

$\mathrm{Si}$ bien es importante disminuir paulatinamente el uso de transporte automotor privado y promover el uso de transporte sostenible, hay un gran temor por parte de la población para el uso de las bicicletas. Según la Municipalidad de Miraflores (2016), entre los principales inconvenientes que encuentran los ciudadanos está la actividad delictiva, falta de estacionamientos para bicicletas, inseguridad frente a vehículos motorizados, falta de una red ciclovial interconectada y de calidad, y de iluminación. 
Es por ello que, dentro de las propuestas del distrito, se encuentra "priorizar la circulación peatonal y el transporte en bicicletas, como modos alternativos de transporte» (Municipalidad de Miraflores 2016). Así, una de las acciones estratégicas dentro del Plan Concertado del Distrito incluye la implementación y mejoramiento de los casi trece kilómetros de ciclovías existentes, para que cuenten con un nivel adecuado de articulación. Adicionalmente, se plantea establecer un sistema de alquiler de bicicleta pública. Este nuevo sistema se integraría al transporte público; lo que permitiría propiciar un transporte intermodal. Sin embargo, la carencia de un servicio completo de estacionamientos para bicicletas imposibilita las conexiones intermodales. (Municipalidad de Miraflores, 2017)

\section{Metodología empleada}

\subsection{Sustento teórico conceptual}

La presente investigación ha definido y perfilado cinco conceptos fundamentales, en los que se puede sustentar la metodología aplicada.

1. Ciclo-inclusividad. El total de vías de tránsito en las ciudades deber ser cicloinclusiva, para que el ciclista pueda transportarse de manera cómoda, segura y conveniente, así como también deben contar con adecuada señalización y facilidades y poder integrarse con el transporte público (MVUC, 2015). Cuando una ciudad no es ciclo-inclusiva, no cuenta con facilidades para los ciclistas, ya que deben compartir la vía con vehículos motorizados o deben utilizar las veredas, lo cual es peligroso y no es considerado atractivo.

2. Rutas seguras. Refiere a la necesidad de que la infraestructura garantice la seguridad de los ciclistas y otros usuarios. Debido a las características inherentes al transporte en bicicleta, los usuarios son más vulnerables, especialmente en relación con los vehículos motorizados. Entre las medidas o elementos que influyen en la seguridad de la infraestructura y la percepción de seguridad de los ciclistas se encuentra el tráfico vehicular adyacente, señalización y semaforización, segregación física del flujo vehicular y alumbrado (Pettinga, 2009).

3. Rutas coherentes. Refiere a qué tan continua y concisa es la ciclovía (AECI, 2012). Así, la infraestructura de ciclovías forma un todo coherente, pues debe proveer conexiones entre todos los puntos de salida y destino, sobre todo los puntos importantes y más concurridos de la ciudad. Una infraestructura coherente ofrece a las personas la posibilidad y facilidad de desplazarse hacia cualquier punto, junto con el uso de otros medios de transporte (AECI, 2012). El ancho y la densidad de la malla de ciclovías son factores importantes de 
cohesión; por ejemplo, el ciclista tiene la opción de elegir entre una vía rápida y transitada o una vía más lenta pero menos transitada.

4. Rutas directas. No se puede ver el ciclismo y el transporte en bicicleta como una forma conveniente de movilizarse si las rutas no son directas (Hembrow, 2008). Lo directo en la ruta significa que los ciclistas puedan utilizar la ruta más directa, con un mínimo de desvíos y con la máxima conveniencia. Los desvíos se evalúan con el factor de desvío, que determina la relación entre la distancia real de la ruta y la distancia euclidiana de la misma. Por otro lado, la conveniencia hace referencia a las paradas ocasionadas por obstrucciones o intersecciones, en las que la bicicleta no tiene prioridad de paso, así se contabiliza cuántas paradas se realizan por kilómetro. Además, se debe tener en cuenta que el tiempo de viaje en comparación con otros medios de transporte como caminar, transporte público o transporte privado debe ser menor o de igual manera.

5. Infraestructura ciclovial. comprende el conjunto de infraestructura ciclovial; vías, intersecciones y espacios urbanos que permiten la movilidad de los ciclistas (Municipalidad Metropolitana de Lima, 2017). Para superar las limitaciones físico-espaciales es fundamental una red ciclovial densa, con una alta conectividad entre los nodos del espacio urbano.

Las dos tipologías generales de ciclovías son vías segregadas y no segregadas. Las vías segregadas cuentan con una separación física por un elemento separador y son reservadas para los ciclistas, para asegurar su seguridad. Estas pueden encontrarse a nivel de pista o vereda, por lo general cubren grandes distancias y conforman la red principal de infraestructura ciclovial. Las vías segregadas se pueden clasificar como ciclovías o cicloaceras - las ciclovías se encuentran integradas a la pista y pueden ser tanto unidireccionales como bidireccionales, mientras que las cicloaceras se encuentran integradas a las veredas o espacios compartidos con peatones-. Por el contrario, en las vías no segregadas, el ciclista tiene total prioridad y circula al mismo nivel que los vehículos motorizados. Por ello deben ser implementadas en vías con bajo flujo vehicular y velocidad. Entre las vías no segregadas se encuentran los ciclocarriles: una franja delimitada a nivel de la pista para la circulación de ciclistas estrictamente en sentido unidireccional

\subsection{Esquema de procesamiento y análisis}

La metodología propuesta para la evaluación de la infraestructura ciclovial de Miraflores está estructurada en cuatro fases, las cuales comienzan con el levantamiento y cartografía de detalle del conjunto de ciclovías, para, a continuación, poder determinar los índices y variables que permiten evaluar la seguridad, coherencia y grado de dirección de estas, a partir del levantamiento de la red vial y su evaluación (Figura 4). 
Figura 4. Flujograma de la metodología empleada

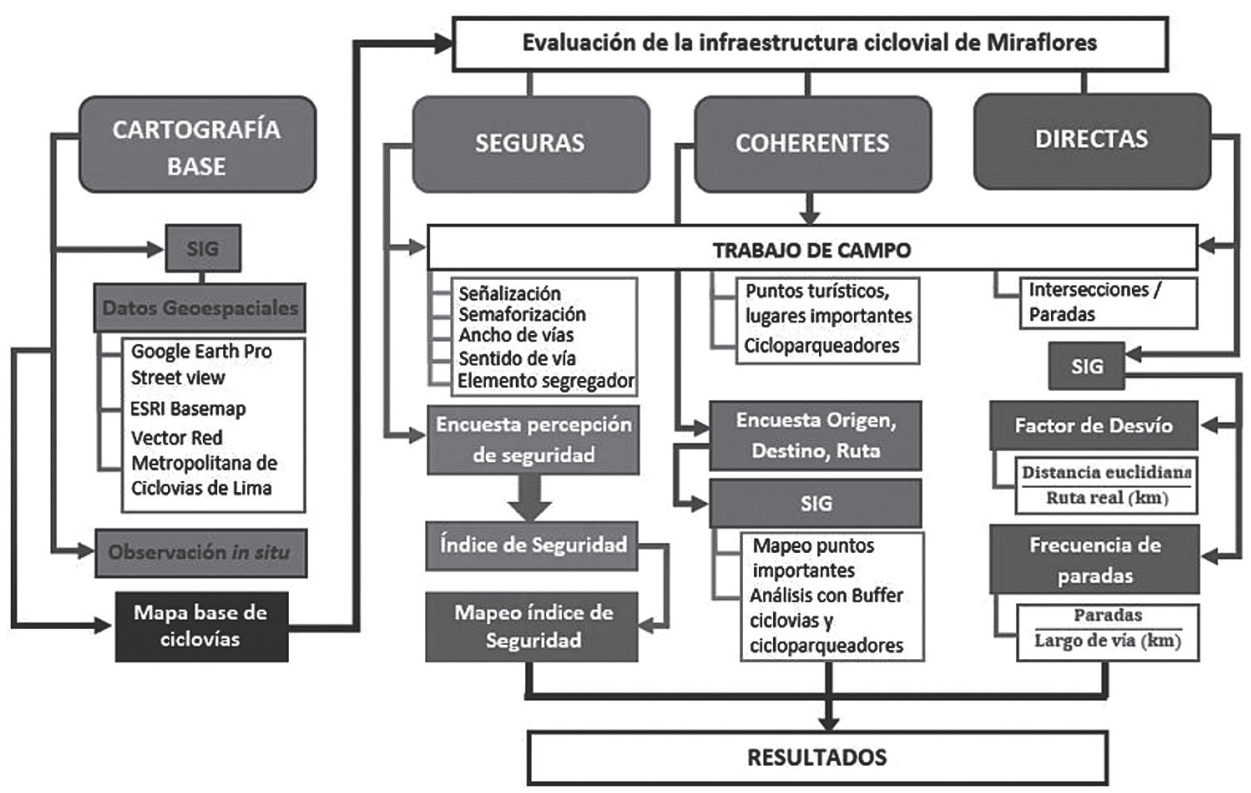

A continuación, se detalla el desarrollo de cada una de las fases.

\subsubsection{Cartografía base}

Con el objetivo de evaluar la infraestructura actual de las ciclovías del distrito de Miraflores se desarrolló una cartografía base de la configuración espacial de la red de ciclovías. Para ello se utilizó un Sistemas de Información Geográfica (SIG), específicamente el software ArcGIS 10.3, mediante el cual se digitalizaron las ciclovías de Miraflores, junto con sus atributos principales.

La información fue obtenida de fuentes primarias y secundarias. La de fuentes primarias se obtuvo in situ, mediante el recorrido de las ciclovías de Miraflores, mientras que la información de fuentes secundarias consistió en el archivo vectorial de la Red Metropolitana de ciclovías de Lima descargado de Google Maps y el «Eco mapa» de Miraflores con las ciclovías actuales y proyectadas. Para validar el vector se utilizó el ESRI Basemap satelital y vial y el Street View. No obstante, estos recursos presentaron limitaciones tanto por la resolución espacial como temporal. Es por ello que fue fundamental adquirir información mediante trabajo de campo, en el cual se recorrió las ciclovías de Miraflores y con la ayuda de GPS y una ficha de observación, se registraron sus atributos, para luego ser digitalizados en ArcGIS. 


\subsubsection{Rutas seguras}

Dada la limitada disponibilidad de información sobre las ciclovías de Miraflores, se analizó su seguridad mediante la combinación de observación de la infraestructura y la aplicación de encuestas de percepción de seguridad a los ciclistas. Ambos métodos tienen un carácter complementario; por un lado, la encuesta permite una aproximación a la percepción de los ciclistas y por otro lado, la observación representa una evaluación objetiva y directa de la seguridad de la infraestructura. En comparación, permite identificar coincidencias entre la percepción de seguridad y la realidad. Tanto para la observación como para la encuesta, se consideraron seis variables de seguridad de ciclovías: elemento segregador, señalización y semaforización, ancho de vía, sentido de vía y alumbrado público (Gurine, 2016). En el trabajo de campo se observó, midió y registró las variables de seguridad para luego digitalizarlas.

Se aplicaron virtualmente encuestas de percepción de seguridad de las ciclovías a una muestra de cuarenta personas. En la primera sección de la encuesta, se presentaron las seis variables de seguridad y se les indicó a los participantes que les asignaran un puntaje entre 1 y 6 (siendo 1 , "poco importante» y 6 , «muy importante»). Ello fue realizado con la finalidad de asignarle un peso representativo de la percepción de los ciclistas a cada variable (Saplioglu \& Yüzer, 2016). En la segunda sección de la encuesta se presentó cada ciclovía por separado y los participantes debían indicar la seguridad de cada variable (siendo 1, «muy baja» y 5, «muy alta»). Tras la realización de las encuestas, las respuestas fueron sistematizadas y procesadas en Excel. Luego, se construyó y calculó el índice de percepción de seguridad, el cual fue representado cartográficamente.

\subsubsection{Rutas coherentes}

El análisis de la coherencia de las ciclovías de Miraflores se realizó en tres etapas, a través de las cuales se determinó la capacidad de la infraestructura ciclovial (ciclovías y parqueo para ciclos «cicloparqueadores») para proveer conexiones entre los principales puntos de origen y destino de los usuarios. En la primera etapa se realizó trabajo de campo, en el que se identificó la presencia de parqueos para ciclos a lo largo de las ciclovías, ya que esta infraestructura proporciona seguridad para la bicicleta del viajero cuando llega a su destino (Pettinga, 2009). Asimismo, se identificaron puntos importantes dentro del distrito, tal como atractivos turísticos, equipamientos urbanos públicos y privados como parques, iglesias, museos, centros comerciales y centros educativos. Sin embargo, se excluyó del análisis la mayor parte del sector socioeconómico más elevado de Miraflores, al este de la avenida Paseo de la República, por no contar con ciclovías.

En la segunda etapa, se aplicó una versión adaptada del método OLIVE que tiene como objetivo conocer las características de los viajes en bicicleta (Suzuki et al., 2012). 
Fue así como se obtuvo información del viaje de los ciclistas de Miraflores, mediante la realización de encuestas virtuales para conocer el origen, destino y la distancia medida, que estarían dispuestos a caminar para estacionar su bicicleta. Dicha información, fue necesaria para obtener los puntos más importantes de las rutas de los ciclistas en Miraflores, para luego analizar la conectividad y accesibilidad de dichos puntos desde las ciclovías.

Por último, en la tercera etapa se integró la información de la infraestructura de ciclovías, los puntos más importantes de viaje (origen y destino) y los parqueos de ciclos utilizando ArcGIS. Luego, se realizaron buffers a las ciclovías de cien y 150 metros, y a los parqueos de ciclos de cien y doscientos metros, para analizar la coherencia de las ciclovías y «cicloparqueadores» en proveer conexiones entre los orígenes y destinos más importantes. Se determinaron dichas distancias para los buffers, considerando los resultados de las encuestas y el promedio de la longitud de las manzanas de Miraflores.

\subsubsection{Rutas directas}

Al evaluar las ciclovías se debe entender a la movilidad urbana como de primordial importancia. Asimismo, se deben identificar las limitaciones para la movilidad de ciclistas (Rodrigue, Comtosis \& Slack., 2006). Dentro de ese marco, se busca medir qué tan directas son las ciclovías y qué limitaciones se presentan para la movilidad de las personas. En manuales de diseño de ciclovías, se establecen dos líneas de análisis para evaluar qué tan directas son las ciclovías; por un lado, en función a la distancia y por otro al tiempo de viaje (AECI, 2012).

En primer lugar, se evaluó el carácter directo de las ciclovías en función a la distancia, atributo central del transporte y puede ser una simple distancia euclidiana hasta una distancia logística (Rodrigue et al., 2006). El método utilizado fue el factor de desvío, el cual es la diferencia entre la distancia euclidiana y la distancia más corta utilizando la red de ciclovías entre puntos de origen y destino (AECI, 2012). Para la selección de rutas se escogieron tres puntos de origen y cuatro puntos de destino. Los puntos de origen se ubican dentro de las mismas ciclovías en el límite distrital, mientras los puntos de destino representan los lugares que podrían ser los más visitados del distrito, que fueron el parque Kennedy, el Centro Comercial Larcomar, las losas deportivas y el Skatepark. Se combinaron los diversos puntos de inicio y destino para establecer doce rutas diferentes. Fue con base en estas rutas que se calculó el factor de desvío.

Para medir el carácter directo de las ciclovías en función al tiempo, se calculó el índice de conveniencia, una relación numérica entre el número de paradas/intersecciones que debe hacer un ciclista por cada kilómetro de la ruta. Para ello, se identificó mediante el trabajo de campo la presencia de intersecciones/paradas y se empleó, además, la información base de semáforos. Adicionalmente, en ArcGIS se calculó la extensión de las ciclovías y de ese modo se calculó la frecuencia de paradas por kilómetro. 


\section{RESULTADOS Y Discusión}

\subsection{Cartografía base}

En total, el distrito Miraflores, cuenta con una red ciclovial de 13,36 km, con una configuración espacial dispar. Es decir, la cobertura de la red no es completa y la red no es descentralizada, sino se encuentra altamente centralizada (Figura 5).

Miraflores se encuentra dividido en tres sectores socioeconómicos A, B y C, de los cuales el B y C presentan infraestructura ciclovial, mientras que el sector A (A1 y A2) se encuentra desatendido. En el plan de desarrollo concertado del distrito y el Eco Mapa, se evidencia un interés por expandir la red ciclovial, a fin de permitir una movilidad efectiva por todo el distrito, al igual que una alta transportabilidad. Ya hay una proyección de la construcción o habilitación de 33,60 km de nuevas ciclovías, hacia los sectores desatendidos y para complementar los sectores que ya cuentan con infraestructura ciclovial.

Se clasificó la infraestructura ciclovial del distrito según la tipología establecida por la Municipalidad de Lima (2017), tras lo cual es posible apreciar el predominio de las vías segregadas $(11,07 \mathrm{~km})$, de las cuales la mayor extensión corresponde a cicloaceras (malecón de Miraflores, Av. José Pardo y Av. Arequipa). Por otro lado, hay una menor extensión de vías no segregadas $(2,29 \mathrm{~km})$ de ciclocarriles en el distrito (Av. Bolognesi, Av. 28 de Julio y Av. La Paz).

Figura 5. Tipología de la red ciclovial de Miraflores

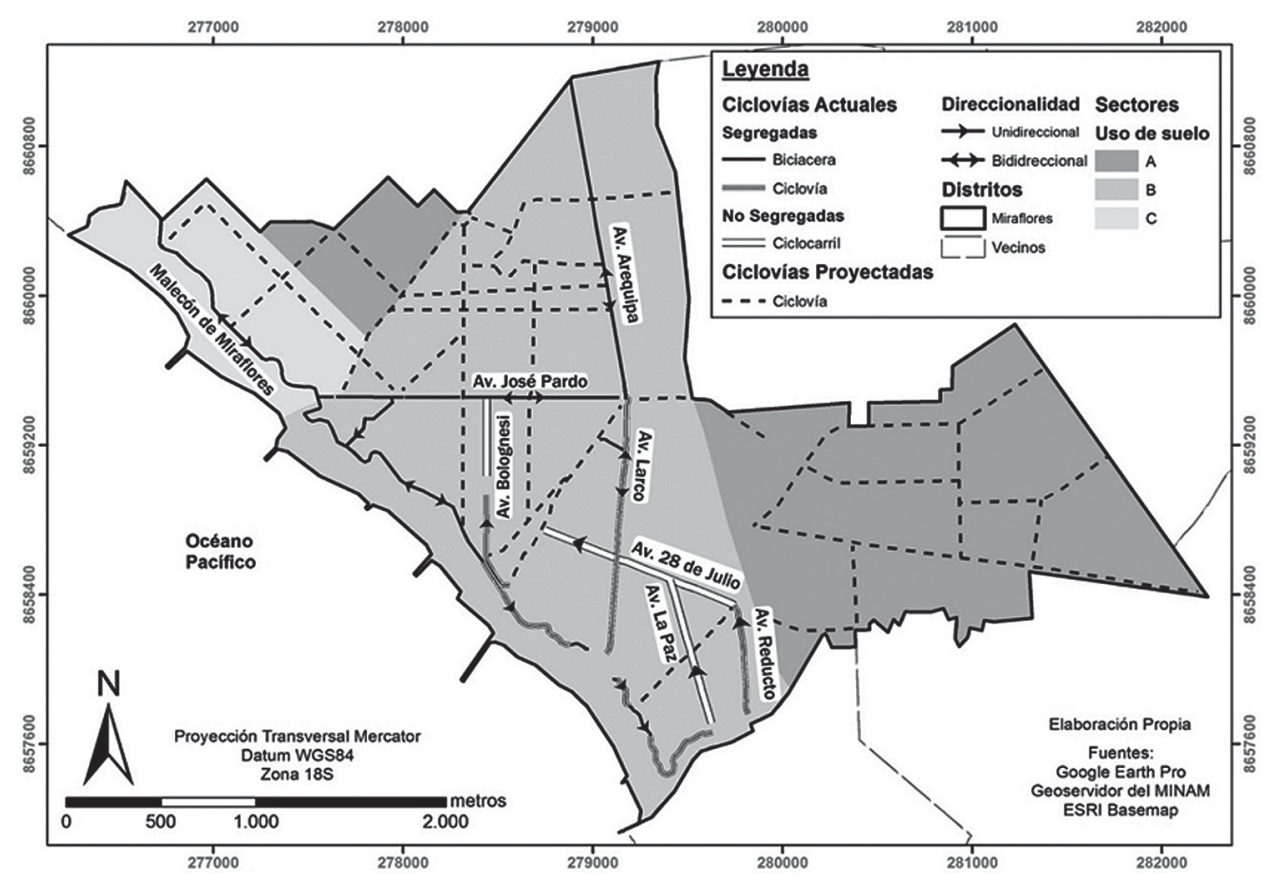


Lo anterior demuestra que en el distrito se prefiere la implementación de infraestructura ciclovial segregada, la cual se basa en proveer al ciclista una separación física de los carriles adyacentes para vehículos motorizados (Figura 6).

Figura 6. Ejemplos de ciclovías en el distrito de Miraflores, tipología, elemento segregador y sentido de vía: a., Ciclocarril, Pintura, Unidireccional; b., Ciclovía, Bordillo continuo, Unidireccional; c., Ciclovía, Bordillo intercalado, Unidireccional; d., Ciclovía, Ojos de gato, Unidireccional; e., Cicloacera, Sardinel, Bidireccional.

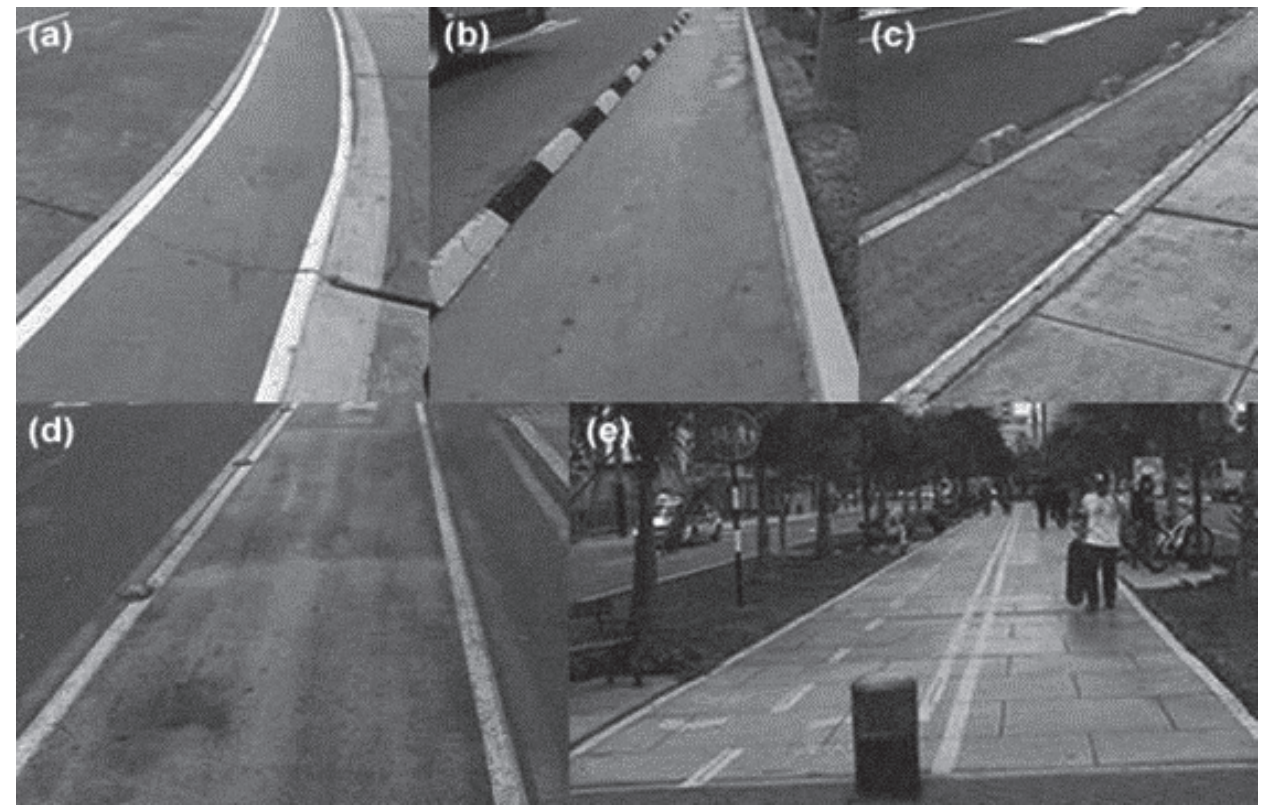

\subsection{Seguridad}

La seguridad de las ciclovías fue evaluada mediante la observación in situ de la infraestructura ciclovial y la aplicación de encuestas de percepción de seguridad a los ciclistas.

\subsubsection{Observación in situ}

Los resultados de la observación in situ destacan que se han empleado diversos elementos segregadores, clasificados según el manual de la Municipalidad de Lima (2017). Entre los elementos segregadores que proveen una separación física se encuentran los bordillos continuos e intercalados, sardinel y ojos de gato; por otro lado, se encuentra la pintura la cual es utilizada de manera general en todas las ciclovías (de color rojo).

Las ciclovías de Miraflores cuentan con un ancho que varía desde uno hasta 2,8 metros. Se identifica una relación entre el ancho de las ciclovías y su tipología, es así 
como los ciclocarriles tienen un menor ancho (un metro), mientras que las ciclovías tienen un ancho más variado (entre uno y 1,8 metros) y las cicloaceras como la de la Av. José Pardo tiene el mayor ancho (2,8 metros). Asimismo, cabe resaltar que no existe una relación evidente entre el ancho de las ciclovías y el sentido vial de estas. Los ciclocarriles, por normativa, deben ser de un solo sentido; no obstante, las ciclovías y cicloaceras pueden ser uni o bidireccionales. Es así como se identifican tanto cicloaceras bidireccionales con un ancho mínimo (1,1 metros), como con uno máximo (2,8 metros).

Adicionalmente, manuales de diseño de infraestructura ciclovial consideran la importancia de una adecuada señalización, la cual puede ser horizontal (demarcación) o vertical. Todas las ciclovías de Miraflores cuentan con señalización horizontal reglamentaria, la cual indica la función de la vía y sentidos viales; y señalización preventiva, referida a puntos de detención (exclusivamente en intersecciones). Por el contrario, la señalización vertical es casi nula y se concentra primordialmente en las ciclovías de la avenida Larco y avenida Arequipa. Además, en las intersecciones de la avenida Larco hay semáforos para ciclistas.

Si bien en Lima Metropolitana existe el Manual de Dispositivos de Control de Tránsito Automotor para Calles y Carreteras (2016), el diseño de ciclovías no ha considerado la señalización vertical y ha priorizado la horizontal. En la avenida Larco la señalización vertical corresponde a la señal vigente R-42-Ciclovía, la cual notifica a los usuarios la existencia de una vía exclusiva para el tránsito de bicicletas. Por otro lado, en la avenida Arequipa la señal vigente instalada es la R-42C-Circulación no compartida, la cual establece la obligación que tienen el ciclista y el peatón de circular por la vía que les corresponde (Municipalidad de Lima, 2017). Es importante resaltar el hecho, de que no se han instalado señales de carácter preventivo para asegurar la seguridad de los ciclistas.

\subsubsection{Encuestas de percepción de seguridad}

En la primera sección de la encuesta de percepción de seguridad, se les pidió a los participantes asignar un valor de importancia para cada variable de seguridad. Se calculó la media de los puntajes que los 40 participantes le asignaron a cada variable. Además, se calculó la desviación estándar y moda. Las variables que obtuvieron la media más elevada fueron tráfico vehicular, elemento segregador y ancho de vía. Por el contrario, las variables con menor puntaje fueron alumbrado público y sentido vial. De acuerdo con el puntaje medio, se le asignó un peso a cada variable, para luego generar el índice de seguridad.

$$
\text { Índice de Seguridad }=\sum_{i=1}^{i=6} \frac{x(i)}{6}
$$


El índice de seguridad fue calculado para los nueve segmentos de ciclovías identificadas en el distrito, siendo la ciclovía de la avenida José Pardo la de mayor puntaje y la avenida 28 de Julio con el menor. Posteriormente, en ArcGIS se digitalizaron los puntajes del índice y se realizó una clasificación en cinco clases, a las cuales se les asignó una calificación entre A y E, en el cual las ciclovías con una calificación A-B son las percibidas por los ciclistas como las más seguras y las D-E como las más inseguras (Figura 7).

Tanto los resultados de la observación in situ como la percepción de seguridad de los ciclistas proveen información importante sobre la seguridad de las ciclovías de Miraflores. Sin embargo, es posible generar información más valiosa, si es que se comparan ambos resultados en busca de correlaciones. En primer lugar, se puede identificar una relación directa entre la tipología de la infraestructura ciclovial y la percepción de seguridad. Las vías segregadas, presentan un puntaje más elevado de seguridad, especialmente las cicloaceras. Por el contrario, las vías no segregadas (ciclocarriles) evidencian la menor seguridad percibida por los usuarios.

Los resultados del cálculo del índice de seguridad demuestran que los usuarios perciben las ciclovías de la avenida José Pardo y la avenida Arequipa como las más seguras, mientras que la de la avenida 28 de Julio como la más insegura. Al ser el elemento segregador y el ancho vial las variables de seguridad más importantes para los usuarios, se puede identificar una relación con su diseño actual. Ambas ciclovías

Figura 7. Índice de seguridad de las ciclovías de Miraflores

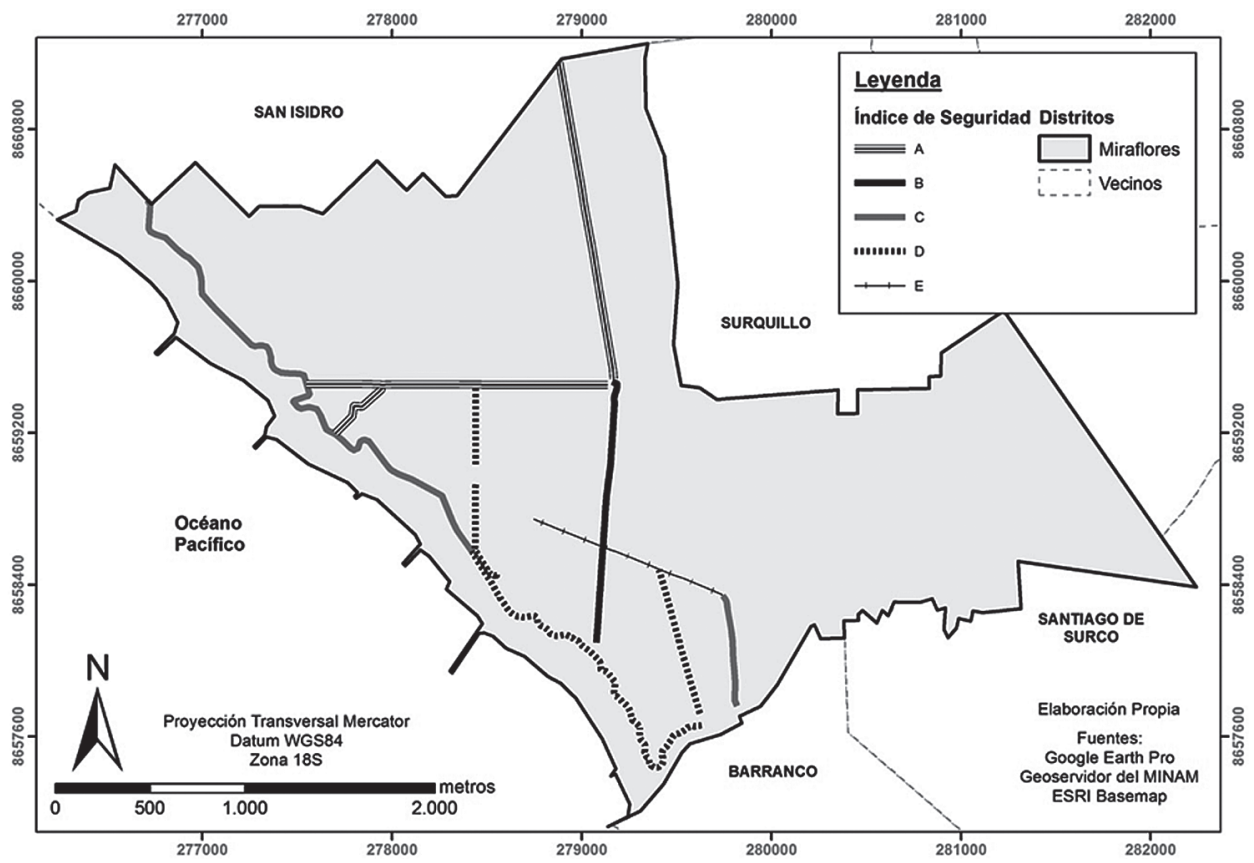


son las únicas en el distrito segregadas por un sardinel en berma central; es decir, se encuentran totalmente aisladas del tráfico vehicular adyacente. Asimismo, cuentan con el mayor ancho vial (entre dos y 2,8 metros) lo cual genera una movilidad urbana más segura. También se encuentran las ciclovías con menor clasificación de seguridad (D-E), las cuales coincidentemente, son vías no segregadas (ciclocarriles) de modo que no se encuentran aisladas de los vehículos motorizados más que por pintura reglamentaria. Asimismo, son angostas (un metro) y carecen de señalización vertical. El único caso de ciclovía con calificación baja que es una vía segregada es el segmento del malecón de Miraflores (desde puente Villena hasta bajada Armendáriz). Si bien la ciclovía se encuentra segregada, el elemento segregador predominante es el bordillo intercalado, el cual provee una menor separación del tráfico adyacente.

Es importante resaltar que la ciclovía que cuenta con un mayor puntaje de seguridad es la de la avenida José Pardo. Ello se presenta como paradójico, visto que, si bien la Municipalidad de Miraflores la considera como una ciclovía, en realidad es una berma central para el paso peatonal. No obstante, dicho paso peatonal es ampliamente utilizado por ciclistas y considerado como el más seguro. Si bien la «ciclovía» de la Av. José Pardo no cuenta con la señalización reglamentaria, su diseño, en general, —ancho y con segregación del tránsito vehicular - ha atraído a los ciclistas. A ello se suma su gran extensión y su función como vía arterial del distrito.

\subsubsection{Coherencia}

La coherencia de las ciclovías se evaluó mediante la recolección de datos in situ de la ubicación de "cicloparqueadores» y de los puntos más importantes del distrito para los ciclistas. Para determinar los puntos de destino fueron considerados varios tipos de establecimientos (comerciales, culturales, recreacionales, institucionales) que fueran accesibles en bicicleta. Una segunda fuente de información consistió en las encuestas que proporcionaron información sobre otros puntos importantes de destino, así como de comportamiento y utilización de la infraestructura ciclovial (Figura 8).

De esta manera, se ubicaron los puntos más importantes de destino de las personas encuestadas y los puntos considerados de la evaluación in situ. Luego, se aplicaron dos buffers, de cien y 150 metros, para observar la distancia de los puntos importantes de las ciclovías. Se observó que no hay mucha diferencia entre ambos buffers en cuanto a puntos importantes en su área de influencia. De un total de 61 puntos importantes, se obtuvieron dieciséis en el buffer de cien metros, en los que resaltan los de comercios, y se obtuvieron doce puntos importantes en el de 150 metros compuesto por parques, restaurantes y comercios. Así, considerando el buffer de cien metros, se obtiene que las ciclovías existentes conectan al distrito con el 26\% de puntos importantes, mientras que los resultados para el buffer de 150 metros, permite la conexión con solo el 19\% 
de puntos y, en total, ambos generaron una conexión con el $45 \%$ de puntos. Se puede afirmar que la coherencia de la red ciclovial es deficiente. En este sentido, se puede observar en la Figura 8, que el sector A del distrito está completamente desconectado de la red ciclovial así, como una parte significativa del sector B, lo que afecta negativamente la coherencia de la red ciclovial, en el sentido de que restringe los posibles puntos de origen y destino de los ciclistas al hacer uso de esta.

Se obtuvo que el principal motivo del uso de la bicicleta es recreativo, con un $44 \%$ de los encuestados, seguido en importancia por la actividad de compra (23\%) y el $33 \%$ por motivos de trabajo o de estudio. La mitad de los encuestados indicó como destino de sus viajes al malecón de Miraflores, al parque Central de Miraflores y a otros parques del distrito. Así, es posible afirmar que la mayoría de las personas encuestadas tuvieron como principal motivación usar sus bicicletas, para desplazarse hacia las áreas verdes del distrito, con motivo de recreación.

De esta manera, se ubicaron los puntos más importantes de destino de las personas encuestadas y los puntos considerados de la evaluación in situ. Luego, se aplicaron dos buffers, de cien y 150 metros, para observar la distancia de los puntos importantes de las ciclovías. Se observó que no hay mucha diferencia entre ambos buffers en cuanto a puntos importantes en su área de influencia. De un total de 61 puntos importantes,

Figura 8. Coherencia de las ciclovías en Miraflores

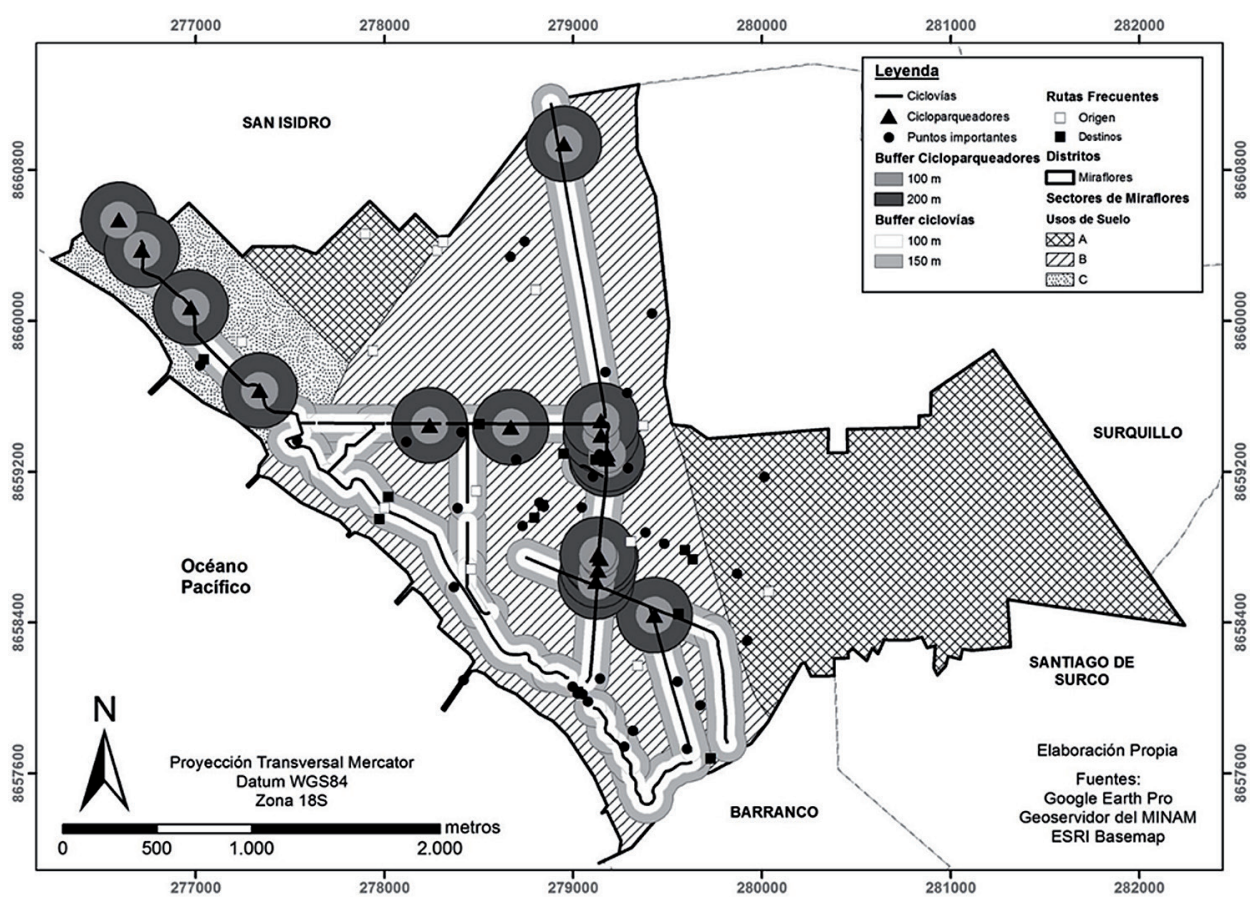


se obtuvieron dieciséis en el buffer de cien metros, en los que resaltan los de comercios, y se obtuvieron doce puntos importantes en el de 150 metros compuesto por parques, restaurantes y comercios. Así, considerando el buffer de cien metros, se obtiene que las ciclovías existentes conectan al distrito con el $26 \%$ de puntos importantes, mientras que los resultados para el buffer de 150 metros, permite la conexión con solo el 19\% de puntos y, en total, ambos generaron una conexión con el $45 \%$ de puntos. Se puede afirmar que la coherencia de la red ciclovial es deficiente. En este sentido, se puede observar en la Figura 8, que el sector A del distrito está completamente desconectado de la red ciclovial así, como una parte significativa del sector B, lo que afecta negativamente la coherencia de la red ciclovial, en el sentido de que restringe los posibles puntos de origen y destino de los ciclistas al hacer uso de la misma.

Se obtuvo que el principal motivo del uso de la bicicleta es recreativo, con un $44 \%$ de los encuestados, seguido en importancia por la actividad de compra (23\%) y el $33 \%$ por motivos de trabajo o de estudio. La mitad de los encuestados indicó como destino de sus viajes al malecón de Miraflores, al parque Central de Miraflores y a otros parques del distrito. Así, es posible afirmar que la mayoría de las personas encuestadas tuvieron como principal motivación usar sus bicicletas, para desplazarse hacia las áreas verdes del distrito, con motivo de recreación.

El 90\% de los encuestados utilizan las ciclovías y con respecto a la frecuencia el $56 \%$ las utiliza regularmente. De esta manera, se puede afirmar que la mayoría de los puntos importantes evaluados no disponen de un espacio adecuado para el estacionamiento de bicicletas, a pesar de que muchas personas utilizan las ciclovías para viajar por Miraflores.

Respecto a los «cicloparqueadores», para el buffer de cien metros, del total de 61 puntos identificados por su importancia, solo dos parques se encuentran incluidos, mientras que, para el segundo buffer de doscientos metros, solo diez de los puntos importantes coincidieron dentro de su área, compuestos por restaurantes y comercios. De esta manera, la ubicación de los «cicloparqueadores» no contribuye a la coherencia de la infraestructura ciclovial, los usuarios no tienen la opción de dejar sus bicicletas en «cicloparqueadores» cuando llegan a sus puntos de destino, a menos que se desplacen mucho más de doscientos metros.

Considerando las recomendaciones sobre la ubicación de los «cicloparqueadores» establecidas en el documento de la Cambridge Cycling Campaign (2008), en las que se señala que los «cicloparqueadores» deben estar lo más cercano posible a la entrada de los puntos de destino, se establecen veinticinco metros, como máximo, para paradas cortas como compras y cincuenta metros para paradas largas como centros de trabajo o de estudio. Al aplicar estas medidas en ArcGIS no se obtuvo puntos dentro de los buffers de veinticinco y cincuenta metros, a pesar de que el $24 \%$ y $31 \%$ de los encuestados respondieron respectivamente, estar dispuestos a caminar esas distancias 
como máximo, mientras solo el $9 \%$ estarían dispuestos a caminar doscientos metros. En consecuencia, la falta de «cicloparqueadores» cercanos a los puntos importantes de destino afecta negativamente la coherencia de la infraestructura ciclovial y la utilización de las bicicletas, ya que las personas no quieren caminar grandes distancias para estacionar su bicicleta y luego tener que caminar hacia sus puntos de destino.

Los «cicloparqueadores» no están distribuidos de manera uniforme: hay dos grupos concentrados, uno en las avenidas José Larco y el parque Central de Miraflores (Kennedy), y el otro grupo se ubica en la parte norte del malecón de Miraflores, pero las unidades están más separadas entre sí, y hay amplios espacios que no cuentan con «cicloparqueadores» como la avenida Arequipa y la mayoría de los parques del malecón. Esta falta de «cicloparqueadores» en el malecón afecta negativamente a los usuarios de las ciclovías, ya que la principal motivación de utilizar bicicletas es la recreativa y los puntos más importantes de destino de las personas encuestadas fueron el malecón y los parques cercanos a este.

En este sentido, la falta de «cicloparqueadores» en puntos importantes, puede influir en la decisión de utilizar la bicicleta como medio de transporte, por ejemplo, para acudir a los parques del malecón con fines de recreación. En este sentido, el 68\% de las personas encuestadas consideraron como media o alta, la influencia de la presencia de «cicloparqueadores» en su decisión de utilizar la bicicleta. En consecuencia, al no haber "cicloparqueadores» cercanos en los principales parques de recreación del distrito de Miraflores, motiva que las personas opten por otros medios de transporte.

\subsubsection{Carácter directo de las ciclovías}

Es complicado evaluar el factor de desvío a menos que se tengan rutas oficiales establecidas, por lo que, en este estudio, se determinaron doce rutas, a partir de la combinación de tres puntos de origen, situados en los límites distritales y que funcionan como las principales entradas al distrito y cuatro puntos de destino, considerados como de máxima afluencia. En la Figura 9, se puede observar la ubicación de estos siete puntos y la red de rutas que se deriva de su comunicación.

En términos del factor de desvío, en la literatura actual se plantea que lo recomendable son valores cercanos a 1,2, con límites máximos entre 1,4 a 1,5 (CEGB, 2017). En general, las rutas analizadas muestran valores cercanos a 1,2, lo que indica que no existe mayor desvío. Solamente en dos rutas, la PO1-PD1 y la PO1-PD2, se superan estos límites máximos con valores de 1,9 y 1,7 respectivamente. En general, la mayoría de las rutas estudiadas presentan valores aceptables en cuanto al nivel de carácter directo. Para obtener un valor más representativo, se tendría que hacer un análisis más extenso de todas las posibilidades de rutas que podrían darse en el distrito, combinando diferentes puntos de origen y de destino. 
Figura 9. Puntos seleccionados para el cálculo del factor de desvío de las ciclovías de Miraflores

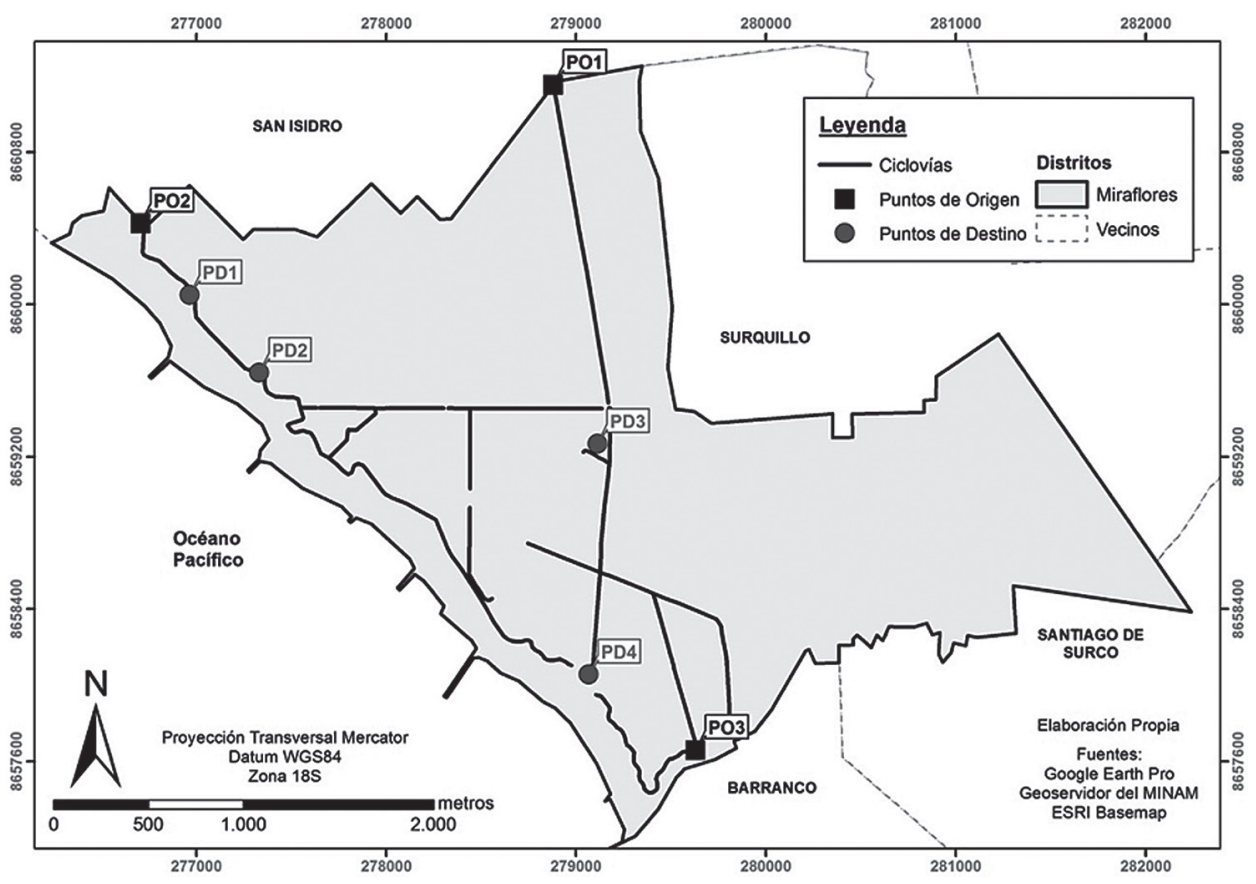

\subsubsection{Indice de conveniencia}

Para este índice se toma en cuenta las paradas por intersecciones y la longitud en kilómetros de las rutas —es decir, cantidad de paradas por kilómetros recorridos—. Los resultados obtenidos, en su gran mayoría, están muy por encima de cero, valor ideal al cual deben de aproximarse las rutas muy convenientes (Queensland Department of Transport, 2014).

En la Figura 10, se representa este índice, en el que se aprecia que solo la ruta del malecón presenta valores entre 0,2 y 3,0, pues no cuenta con intersecciones a excepción de un cruce en uno de sus extremos. Sin embargo, aunque esta ruta puede llegar a ser más directa en términos de intersecciones, es compartida por peatones y por vehículos estacionados, que pueden representar demoras debido a peatones que invaden el carril o vehículos que abren las puertas e interrumpen el paso. Por otro lado, el valor más alto corresponde a la ciclovía de la avenida Larco, con un índice de conveniencia de 11,4. Además, en su mayoría, estas intersecciones cuentan con semáforos para los usuarios ciclistas, lo que le agrega tiempo al desplazamiento. 
Figura 10. Índice de conveniencia de las ciclovías de Miraflores

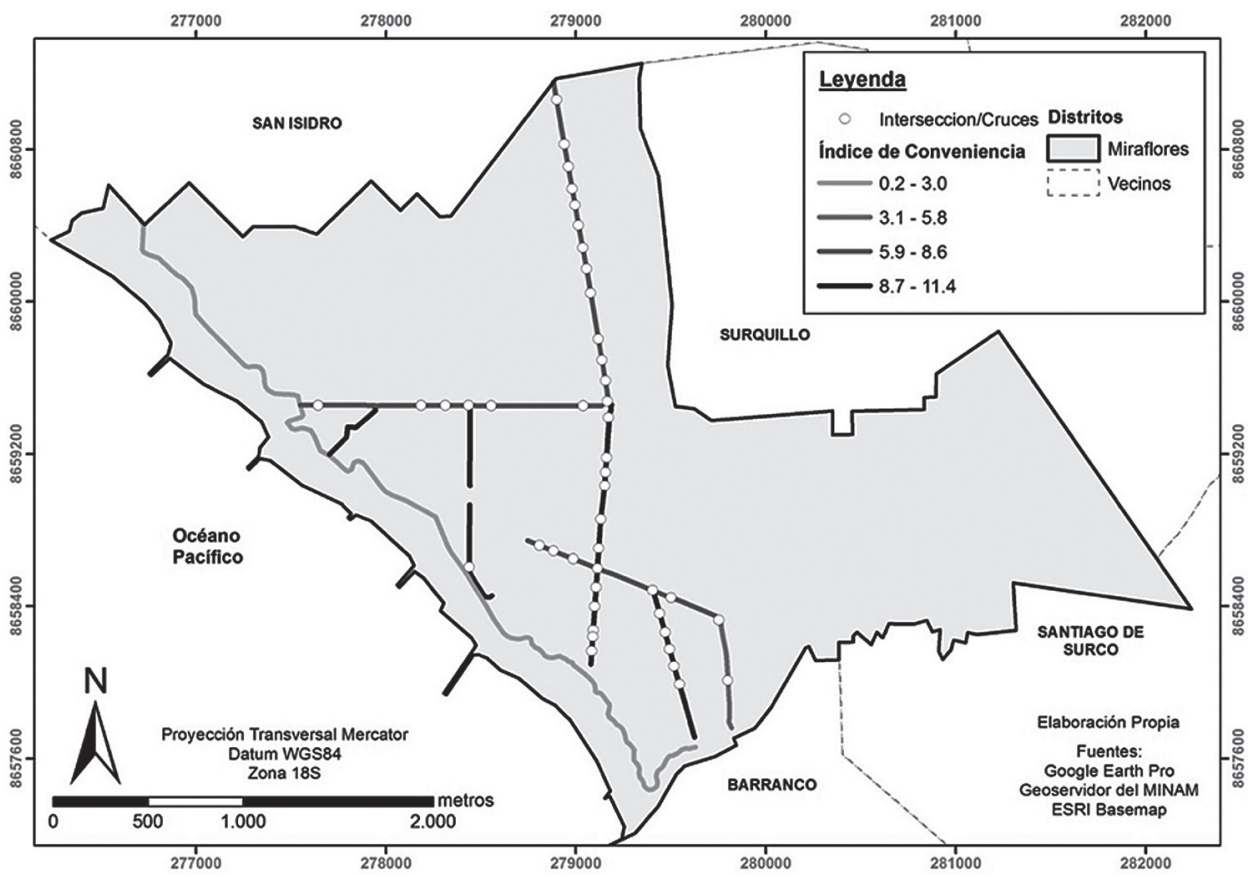

Contrario a lo que ocurre en la ciclovía del malecón, en esta ciclovía se cuenta con elementos segregadores que permiten desplazarse a una distancia prudente de carros y peatones. En promedio, las rutas del distrito presentan un valor de índice de conveniencia de 7,3, o paradas por kilómetro. En general, este valor es alto y puede representar un impedimento para las personas que deseen desplazarse en bicicleta por el distrito de Miraflores. La infraestructura para ciclistas debe apuntar a ofrecer una ventaja en términos de distancia y tiempo por sobre otros modos de transporte, sobre todo el automóvil privado (CEGB, 2017).

Finalizando el desarrollo del presente estudio y producto de la presencia de la COVID-19 en nuestro país, tanto las autoridades de la ciudad de Lima, como los pobladores comienzan a considerar a la bicicleta como un medio de transporte más seguro, como se refleja cuando en el pasado mes de mayo de 2020, la presidenta de la Autoridad de Transporte Urbano (ATU), María Jara, anunció la puesta en marcha de un proyecto que dotará a la ciudad de $301 \mathrm{~km}$ de ciclovías, que se ejecutarán en tres etapas en los distritos limeños y chalacos. El plan se iniciará progresivamente con $142 \mathrm{~km}, 89 \mathrm{~km}$ y $70 \mathrm{~km}$ de ciclovías, respectivamente. Además de integrar la red actual, contempla la estandarización de ciclovías a tres metros de ancho (El Correo, 2020).

De igual manera el Diario Perú 21 en su edición del 18 de julio de 2020, en las principales avenidas del Centro de Lima, es más usual ver a personas a bordo de bicicletas 
para movilizarse en lugar del transporte público, y así evitar el contagio de la COVID-19. Esto es gracias a un conjunto de nuevas ciclovías que han sido habilitadas en los últimos meses para conectar el Centro de Lima con distritos como el Rímac, Lince, San Isidro y Miraflores. De igual forma plantea que, próximamente, también se inaugurarán rutas que conectarán el Rímac con San Martín de Porres e Independencia. Esto permitirá que la bicicleta se vuelva un vehículo alternativo más seguro. (Perú 21, 2020).

En ese mismo sentido, como consecuencia de la irrupción y desarrollo de la pandemia del COVID-19, según refiere Roman, 2020, en su tesis de titulación, comienzan a convivir en las vías de la ciudad de Lima, dos grandes grupos de ciclistas, aquellos que por lo general venían utilizando la bicicleta para asistir a su trabajo o centro de estudio o en ciertos días de descanso como medio de esparcimiento y un nuevo sector que utilizan la bicicleta como medio de desplazamiento y de sustento en el trabajo de reparto a domicilio o delivery. Esto ha representado un incremento no despreciable en el número de personas que utilizan con frecuencia la bicicleta como medio de transporte.

Todo esta situación requiere que en las nuevas inversiones, se tengan en cuenta en su diseño e implementación los diferentes aspectos que se han valorado en la presente investigación, con vistas a lograr un sistema ciclovial para Miraflores y también para Lima, más seguro, coherente, directo e interconectado.

\section{Consideraciones finales}

La evaluación de la infraestructura ciclovial del distrito de Miraflores demuestra que, de manera general, hay ineficiencias en el diseño y en la funcionalidad de las ciclovías en proveer un medio para el transporte por bicicleta. Ello se evidencia tanto a nivel de la seguridad, coherencia y carácter directo de las ciclovías. En ese sentido, para que las ciclovías del distrito sean funcionales y aseguren una movilidad eficiente de los usuarios, su diseño e implementación debe considerar necesariamente la demanda de los usuarios. Previamente y durante el proceso de planificación y diseño, se deben evaluar sus opiniones, necesidades y demandas. Asimismo, es muy necesario la implementación de una red de ciclovías interconectadas, que sean eficientes y promuevan el uso en bicicleta. Existe una gran parte del distrito que se encuentra desatendida, y aunque se tienen ciclovías proyectadas para el futuro, debe cuestionarse si estas en realidad pueden llegar a realizarse, considerando la situación de cada pista o calle y si realmente son viables.

En cuanto a la seguridad, queda claro que en tanto no haya una cultura urbana de ciclismo en Lima Metropolitana o esta se encuentre en estado incipiente, se deberá priorizar y maximizar la seguridad de los usuarios, a fin de promover ciclovías más adecuada para el contexto actual, como las segregadas físicamente de los vehículos motorizados. Asimismo, se debe cumplir con los reglamentos nacionales en cuanto a la adecuada señalización vertical que provean a los ciclistas de mayor seguridad y que eduquen a los 
conductores de automóviles. Por su parte, respecto a la coherencia de las ciclovías, esta es muy deficiente, ya que en muchos casos se torna difícil encontrar una continuidad efectiva a la hora de conectar diversos puntos de origen y de destino de los viajes que desarrollan los ciclistas. Al respecto destacan la exclusión completa del sector A de Miraflores, y de una parte importante al norte del sector $\mathrm{B}$, de la infraestructura ciclovial, lo que resulta en que no haya conexión alguna; y la desigual distribución y baja cobertura de puntos de interés de los "cicloparqueadores», lo que evidencia la necesidad de ubicar puntos de parqueo de ciclos en las principales áreas recreativas, de gran interés de los ciclistas.

Las ciclovías existentes cuentan con numerosas intersecciones que demoran y dificultan el tránsito, pues hacen que los ciclistas se tengan que detener repetidas veces, lo que además de aumentar la duración del recorrido, implica un desgaste físico adicional. Se debe tener ciclovías que, preferentemente, no cuenten con intersecciones o, de tenerlas, que en ellas la bicicleta y el peatón tengan preferencia por encima de los vehículos motorizados. Esto, junto al factor de desvío, refleja que, si bien las rutas estudiadas pueden ser directas, las ciclovías existentes actualmente no son suficientes para movilizarse a través de todo el distrito de manera directa, pues existen varias rutas que requieren desviarse para poder llegar al destino. Debido a esto, el usuario debe utilizar otras rutas alternas que no cuentan con ciclovías para llegar más rápido a su destino, que no siempre son las más seguras.

El distrito de Miraflores tiene un alto potencial para el desarrollo de ciclovías que ayuden a consolidar la imagen del distrito como «eco-amigable» y que impulsen inclusive más el turismo y recreación, sin embargo, dicho potencial no ha sido aprovechado al máximo. Tal es el caso de la Costa Verde, la cual cuenta con infraestructura como malecones, equipamiento urbano, alumbrado público y un elevado valor paisajístico, pero no existen medios para acceder cómodamente a la Costa Verde con bicicletas, ya que predominan puentes peatonales con escaleras empinadas. En ese sentido, la Municipalidad de Miraflores debería incluir a la Costa Verde, un espacio de recreación y turismo clave, en el desarrollo de ciclovías del distrito.

\section{REFERENCIAS}

AECI (2012). Proyecto PRESTO-Promoción de Ciclismo para Todos como un modo de transporte diario. Recuperado de http://www.etra-eu.com/docs/ElectricBicycles.pdf

Beura, S. K., Chellapilla, H., Panda, M. \& Bhuyan, P. K. (2021). Bicycle Comfort Level Rating (BCLR) model for urban street segments in mid-sized cities of India. Journal of Transport \& Health, 20, 100971. https://doi.org/10.1016/j.jth.2020.100971

BID (2015). Ciclo-inclusión en América Latina y el Caribe: guía para impulsar el uso de la bicicleta. Departamento de Infraestructura y Medio Ambiente. Recuperado de https:// publications.iadb.org/handle/11319/6808 
Cambridge Cycling Campaign. (2008). Cambridge Cycle Parking. Guide How to provide Cycle Parking: a step-by-step guide for planners and providers. Cambridge. Recuperado de https:/www.camcycle.org.uk/resources/cycleparking/guide/

CEGB (2017). Directness Dictionary. Recuperado de https://www.cycling-embassy.org. uk/dictionary\%20/directness

CEPAL (2017). Panorama multidimensional del desarrollo urbano en América Latina y el Caribe. Recuperado de https://repositorio.cepal.org/bitstream/handle/11362/41974/1/ S1700257_es.pdf

Gurine, E. (2016). The use and attractiveness of different types of bicycle infrastructure. Recuperado de http://abstracts.aetransport.org/paper/index/id/4878/confid/21

Hembrow, D. (2008). Directness. A View from the Cycle Path. Recuperado de http://www. aviewfromthecyclepath.com/2008/09/directness.html

INEI (2017). Censo Nacional de Población y Vivienda Perú. Recuperado de: http:// censo2017.inei.gob.pe/resultados-definitivos-de-los-censos-nacionales-2017/

Landis, B., Vattikuti, V. \& Brannick, M. (1997). Real-Time Human Perceptions Towards a Bicycle Level of Service. Transportation Research Record, 1578(1), 119-126. https:// doi.org/10.3141/1578-15

Larsen, J.; Patterson, Z. \& El-Geneidy, A. (2013). Build It. But Where ? The Use of Geographic Information Systems in Identifying Locations for New Cycling Infrastructure. International Journal of Sustainable Transportation, 7(4), 299-317. https://doi.org/10 $.1080 / 15568318.2011 .631098$

Municipalidad de Miraflores (2016). Plan Urbano Distrital 2016-2026. Recuperado de: http://www.miraflores.gob.pe/Gestorw3b/files/pdf/9907-22436Plan\%20Urbano\%20 Distrital\%20Miraflores\%202016\%20-\%202026\%20(1).pdf

Municipalidad de Miraflores (2017). Plan de Desarrollo Local Concertado del Distrito de Miraflores. Recuperado de: http://www.miraflores.gob.pe/Gestorw3b/files/pdf/9708-21538Plan\%20de\%20Desarrollo\%20Local\%20Concertado\%20-\%20Final.pdf

Municipalidad Metropolitana de Lima (2017). Manual de Normas Técnicas para la Construcción de Ciclovias y Guía de Circulación de Bicicletas, 2017. Recuperado de http://www. gtu.munlima.gob.pe/sites/default/files/resoluciones/2017/RG.\%20311-2017-GTU.pdf

MVUC (2015). Vialidad Ciclo-Inclusiva Recomendaciones de Diseño. Versión 1. Recuperado de El término transportabilidad es ampliamente usado en estudios técnicos de transporte y está aceptado por la RAE. Significa: Cualidad de transportable. Referido a la facilidad de movilidad.

Observatorio Lima Cómo Vamos (2017). Encuesta Lima Cómo Vamos 2016. Recuperado de http://www.limacomovamos.org/trabajo/descarga-encuesta-lima-como-vamos-2016/ ONU-Habitat (2016). Jornadas de trabajo-Movilidad urbana sostenible y espacio público. Recuperado de: https://nuevassolucionesurbanas.org/nuevajusticianuevaagendaurbana-/pdf/ONUhabitat-Informe 3 -Final-lowres.pdf 
Orellana, D., Hermida, C. \& Osorio, P. (2017). Comprendiendo los patrones de movilidad de ciclistas y peatones. Una síntesis de literatura. Revista Transporte y Territorio, 16, 167-183. Recuperado de http://www.redalyc.org/articulo.oa?id=333051591009

Pantera, J., Guellc, C., Humphreysd, D. \& Ogilviea, D. (2019). Can changing the physical environment promote walking and cycling? A systematic review of what works and how. Health and Place, 58, 1-11. https://doi.org/10.1016/j.healthplace.2019.102161

Pardo, C. \& Sanz, A. (eds.). (2016). Guia de ciclo-infraestructura para ciudades colombianas. Bogotá, Colombia: Ministerio de Transporte de Colombia. Recuperado de https:// www.mintransporte.gov.co/Documentos/documentos del_ministerio/Publicaciones

Pettinga, A., Rouwette, A., Braakman, B., Pardo, C., Kuijper, D., de Jomg, H. \& Godefrooij, T. (2009). Cycling-inclusive policy development: a handbook. Recuperado de http://www.fietsberaad.nl/library/repository/bestanden/Cycling-handbook_secure.pdf

Queensland Department of Transport. (2014). Separated Cycleways Guideline. Recuperado de https://cam.bicyclenetwork.com.au/media/vanilla_content/files/SeparatedCyclewaysGuidelinesQLD.pdf

Ríos, R., Taddia, A., Pardo, C. \& Lleras, N. (2015). Ciclo-inclusión en América Latina y el Caribe: Guia para impulsar el uso de la bicicleta. Recuperado de https://www.researchgate.net/publication/292988390_Ciclo-inclusion_en_America_Latina_y_el_Caribe_ gu\%27ia_para_impulsar_el_uso_de_la_bicicleta

Rodrigue, J., Comtois, C. \& Slack, B. (2006). The Geography of Transport Systems. https:// doi.org/10.1080/10630732.2011.603579

Rodrigue, J., Comtois, C. \& Slack, B. (2017). The Geography of Transport Systems. https:// doi.org/10.4324/9781315618159

Rybarczyk, G. \& Wu, C. (2010). Bicycle facility planning using GIS and multi-criteria decision analysis. Applied Geography, 30(2), 282-293. https://doi.org/10.1016/j. apgeog.2009.08.005

Sanders, P. (2008). Measuring the quality of bicycle routes in Pune, India. (Bachelor Thesis). University of Twente Twentw, India. Recuperado de http://essay.utwente.nl/63278/1 /Sanders_BA_CTW.pdf

Saplioglu, M. \& Yüzer, E. (2016). Investigating the effective parameters of safe bicycle route by using a survey study. Sigma J Eng \& Nat Sci, 7(1), 89-96. Recuperado de file://D:/Users/F.L.C.H/Downloads/YTUJENS-2016-7-1.1432\%20(2).pdf

Suzuki, K., Kanda, Y., Doi, K. \& Tsuchizaki, N. (2012). Proposal and application of a new method for bicycle network planning. Procedia-Social and Behavioral Sciences, 43, 558-570. https://doi.org/10.1016/j.sbspro.2012.04.129

Vigura, C. (2020). Conoce una de las principales ciclovías de Lima en este mapa. Diario Perú 21. Recuperado de https://peru21.pe/lima/ciclovias-bicicletas-conoce-una-delas-principales-ciclovias-de-lima-en-este-mapa-noticia/

Winters, M., Babul, S., Becker, H., Brubacher, J., Chipman, M., Cripton, P. \& Teschke, K. (2012). Safe Cycling: How Do Risk Perceptions Compare with Observed Risk? Canadian Journal Public Health, 103(3), 42-47. https://doi.org/10.1007/BF03403834 